\title{
How to get the most out of your trainees in robotic thoracic surgery- "the coachability languages"
}

\author{
Robert J. Cerfolio, Dana Ferrari-Light \\ Department of Cardiothoracic Surgery, New York University Langone Health, New York, NY, USA \\ Correspondence to: Robert J. Cerfolio, MD, MBA, FACS, FCCP. Department of Cardiothoracic Surgery, New York University Langone Health, 550 \\ 1st Avenue, 15th Floor, New York, NY 10016, USA. Email: Robert.Cerfolio@nyumc.org.
}

\begin{abstract}
We are honored to have been invited to write this piece entitled, "How to get the most out of your trainees in robotic thoracic surgery". Perhaps a better question is "How can we optimally coach and inspire each resident and/ or fellow to maximize their value and potential as people, physicians and surgeons during the span of their career?". As surgeons, we must recognize some of the subtle differences in alignment between ourselves and our trainees, appreciate the value of the trainee within our profession, understand that there is variability to the coaching style that each trainee best responds to, and acknowledge that the success of the people we train-which may be our only true legacy_depends on how we engage and inspire them.
\end{abstract}

Keywords: Education; robotic surgical procedures; thoracic surgical procedures; training support; internship and residency

Submitted Sep 01, 2018. Accepted for publication Nov 22, 2018.

doi: $10.21037 /$ acs.2018.12.05

View this article at: http://dx.doi.org/10.21037/acs.2018.12.05

\section{Statement of problem}

We were asked to respond to the prompt: "How to get the most out of your trainees in robotic thoracic surgery?". It is important to consider why is this a question in the first place. There exists some malalignment between attending surgeons and trainees (1). The attending thoracic surgeon faces increasing pressure to operate quickly and efficiently, especially given the increasing focus on the cost of operative time and the opportunity loss to other patients when operations go longer than they should. We created a novel metric called the surgeon efficiency quality index (SEQI) that is able to quantitatively score and measure the actual value each surgeon delivers to a commonly performed operation $\{\mathrm{SEQI}=[($ relative value unit $) \mathrm{RVU} /$ (operating room) OR time in minutes] $\times$ quality index score for each operation\} (2). Since operative time is a driver of this score, we have noticed we are disincentivized to teach. In addition, surgeons today face increased scrutiny for outcomes both from hospital administration, division and department chiefs, and insurance companies (1).

Teaching an operation adds time, but if done well, there exists a return on investment. It is a humbling and finite opportunity to participate in the training of any physician, including future thoracic surgeons. For these reasons, we believe that perhaps the better question to answer is, "How can we optimally coach and inspire each resident and/or fellow to maximize their value and potential as people, physicians and surgeons during the span of their career?".

\section{Recognize your trainees' coachability language}

First, we need to remember that the resident or fellow who shows up to an operation is a highly selected individual who represents the "best of the best". They have met and exceeded academic and personal expectations set in undergraduate and medical school, and many have then gone on to excel despite the psychological and physical stress inherent to general surgical residency. We are fortunate to have them in our lives. Their youth reenergizes us, they teach us novel and new technology, and they inspire innovation. They help us to grow as mentors and surgeons, and yet often we watch them struggle in the operating room to perform a step or procedure that we 


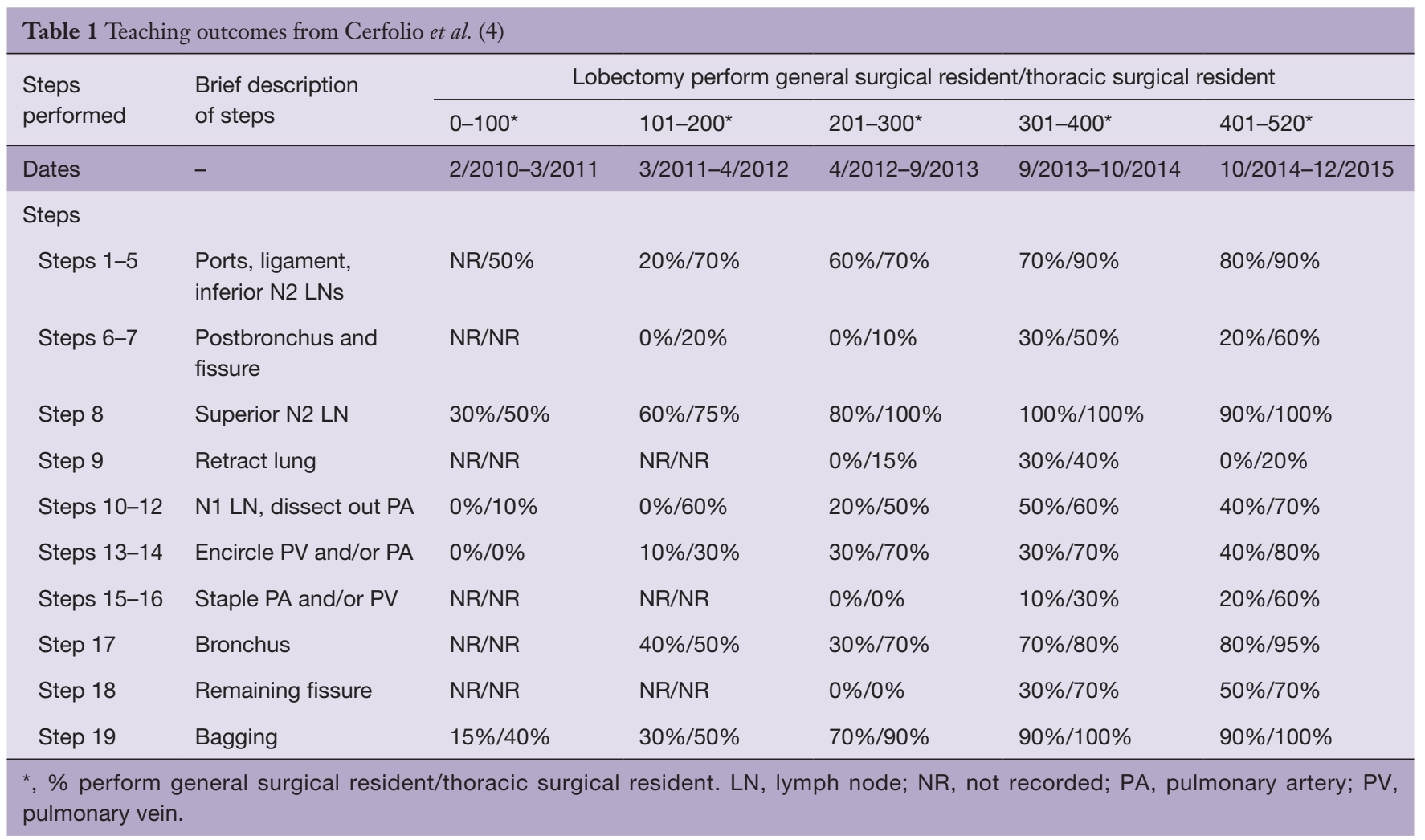

now find so easy. This teaches us humility and patience, two virtues that I still lack but struggle to improve on daily. When we remind ourselves of this prior to starting the operation, the culture of teaching changes-I often find myself allowing the resident to do more and more throughout the course of the operation, and in return, I receive a sense of fulfillment. However, the only way to really know how well you are teaching is to carefully measure it objectively. In our previously published paper, we recorded a 5-year study that patients could enjoy outstanding outcomes with high quality and efficient operations (under 2 hours from skin-to-skin for robotic lobectomy with complete thoracic lymphadenectomy) while teaching (3). As shown in Table 1, in some steps such as encircling the pulmonary vein or artery, the general surgical residents and thoracic fellows completed literally $0 \%$ of these tasks at the start of the study, because we as attending surgeons were still learning how to do it.

However, over time during lobectomy 400-520, they performed $40 \%$ and $70 \%$ of the surgery respectively (3). It was only the compilation of data and the harsh reality of honest facts and self-recorded evidence of my poor underperformance as a teacher that inspired me to teach and be better. We believe these principles have already been applied at other institutions with even better results.

\section{Learn to stop harshly criticizing in the operating room}

I have finally learned to almost completely stop harshly criticizing in the operating room. I have recognized that yelling rarely helps people perform better. While a few trainees do respond to this type of coaching, the vast majority do not and are more effective when they receive positive reinforcement. Coaching, like leadership, requires a diverse set of skills and instruments to have ready at all times in your "coaching toolkit". Leadership and teaching, as I have recently described in my third book Inspire (5), is very similar to golf-many different clubs/skill sets are needed to perform well. Additionally, the key to golf (and coaching) is not only to be able to use every club well, but more importantly to know when best to select each different club. Sometimes it is best to select "words of encouragement" or "a pat on the back" or perhaps a few "words of compliments" that lead to improved trainee performance. Sometimes various levels of disappointment 
can inspire an engaged trainee. I often see a surgical resident prepare much better the next day for surgery when I subtly inspire them by saying "I was very disappointed with your performance today." The right words at the right time if appropriately chosen can motivate the right student. I have learned over the years that the selection of the appropriate tool is perhaps the single most important part of coaching.

Recent studies have affirmed that most surgical trainees are highly motivated and require acknowledgement of achievement by their mentors in order to reinforce proper technique (6-8). This manifests as continuously rewarding the resident during the operation with words of affirmation, and at times handing over the robotic controls and leaving the second console to use the teaching screen to illustrate a point to other members in the operating room as the resident operates independently.

\section{Individualize your coaching style}

In Dr. Chapman's famous book "The Five Love Languages", he lists five love language styles-words of affirmation, quality time, physical touch, receiving gifts, and acts of service (9). Similarly, we believe that there are also a finite number of coachability languages or styles that people respond best to. Most of us experience all of these and respond to them at different times, especially when learning something new and challenging. We have begun the process of labeling the "Eight Coachability Styles" and present some of our early thoughts in this manuscript. The eight coachability styles we have found in trainees are as follows:

(I) Responds best to words of praise;

(II) Responds best to a challenge and competition;

(III) Responds best to evidence-based data and informatics;

(IV) Responds best to coach/mentor's disappointment;

(V) Responds best to the team's reliance on their role;

(VI) Responds best to a sense of pride/accomplishment, motivated by a cause bigger then themselves;

(VII) Responds best to physical praise (pat on back, high five, hug);

(VIII) Responds best to hardware (trophy, money, political or professional status and/or title).

We all possess all of these styles at one point in our life. The best coaches know which instrument or "club" to pull from their toolkit and how and when to best apply it differently for each trainee. Every coach must be able to use all of the instruments and every trainee will respond differently — and to one or another at different parts of their educational process $(7,10)$. Although this suggests high variability and a personalized training program for each resident, the reality is most of this can be standardized.

\section{Keys to success}

We and others have outlined how to best train surgical residents. First, it is important to base a training program on the surgeon and trainee's previous experience-for example, if the trainee is a 55-year old world-class videoassisted thoracoscopic surgeon just learning robotic surgery, their pathway will be different than a first-year surgical resident. However, the stages of competency remain the same and are no different when learning on a robotic platform. Proper selection of both patients and surgeons are tantamount, and unfortunately not everyone can be a robotic thoracic surgeon. Necessary keys to success include a volume of at least 30 anatomic pulmonary resections per year, access to a robot at least once a week, a dedicated operative bedside assistant and a consistent team to care for the patient postoperatively. These characteristics are the minimal requirements.

A competent robotic thoracic surgeon should be: (I) aware of the entire cockpit experience of the robotic console (aware of all buttons, pedals, hand controls, clutches, alarms, options, etc.), (II) have completed at least 19 of the current 30 simulation exercises with a score of at least $80 \%$ prior to any interaction with human tissue and skill at using the fourth-arm, (III) observation of an experienced team, (IV) cadaveric training of the surgeon and the team if possible (V) review of online multimedia/videos and teaching, (VI) a commitment from their administration and/or their attendee and (VII) a progression from level I to level II to level III operations as shown in Table 2 (4).

\section{Legacy}

We are incredibly fortunate as thoracic surgeons, as is any coach or mentor, to be able to be able to concomitantly practice and teach our craft to others who will carry on long after we have moved on. Although there may be no greater honor than taking care of a patient, training a young, eager mind is close. We are blessed with the opportunity to leave a legacy through the next generation of trainees. We submit our greatest legacy is our direct family members and the people we have the great opportunity to educate. When we view medical students, residents and fellows as our 
Table 2 Classification of level I, II and III operations for thoracic surgeons, from Cerfolio et al. (4)

Level I operations

Resection of anterior and posterior mediastinal mass or cyst (if $<3 \mathrm{~cm}$ and not invasive)

Resection of esophageal or pulmonary mediastinal cyst

Lymph node removal

Wedge resection of lung, not directed for a specific nodule*

Sympathotomy*

Resection of a solitary fibrous pleural tumor (if $<3 \mathrm{~cm}$ )

Pleural biopsy*

\section{Level II operations}

Thymectomy for myasthenia gravis

Resection of inferior (lower than $9^{\text {th }}$ rib) posterior mediastinal tumors

Diaphragm plication

Leiomyoma of mid-esophagus

Esophagectomy in chest without anastomosis

Chest wall resection

Level III operations

Segmentectomy

Lobectomy

Pulmonary sleeve resection

Myotomy of esophagus for achalasia with Dor fundoplication

Robotic Ivor Lewis esophagectomy

*, VATS may be preferred technique but reasonable to use robot for training to increase robotic experience. VATS, video-assisted thoracoscopic surgery.

children, we do best when we learn to lament their failures with increased kindness and their successes with greater pride and less credit. The hallmark of a successful (robotic surgeon) person is his or her ability to inspire and mentor those around them to help create and blaze a smoother pathway for those to follow.

\section{Conclusions}

Surgical residents and fellows are a highly valued and integral part of any surgical team. Through standardized, graduated, and yet personalized coaching, we are granted the opportunity to inspire and motivate some of the most talented and intelligent people in the world, who have already chosen to dedicate their lives and talents for the care of patients. We optimize the teaching process when we better understand their different "coachability languages" they bring as well as the teaching styles that we possess in out teaching and coaching tool kit. As we become better teachers and better develop our tool kit, we learn how and when to best use the different teaching and coaching styles and when best to apply it to different residents at different times in order to "get the most" out of our trainees.

\section{Acknowledgements}

None.

\section{Footnote}

Conflicts of Interest: Dr. Cerfolio discloses relationships with Bovie, Community Health Services, Covidien/Medtronic, C-SATS, Davol/Bard, Ethicon, Google/Verb, Intuitive Surgical, KCI/Acelity Company, Myriad Genetics, Pinnacle, ROLO-7 Consulting Firm and TEGO Corporation. Dr. Ferrari-Light has no conflicts of interest to declare.

\section{References}

1. Cerfolio R. Solving the American Healthcare Crisis. Brookline, MA: Business Ghost, Inc., 2018.

2. Cerfolio RJ. Lean, Efficient, and Profitable Operating Rooms: How I Teach It. Ann Thorac Surg 2018;105:991-3.

3. Cerfolio RJ, Cichos KH, Wei B, et al. Robotic lobectomy can be taught while maintaining quality patient outcomes. J Thorac Cardiovasc Surg 2016;152:991-7.

4. Cerfolio RJ, Bryant AS. How to teach robotic pulmonary resection. Semin Thorac Cardiovasc Surg 2013;25:76-82.

5. Cerfolio R. Inspire. Brookline, MA: Business Ghost, Inc., 2017.

6. Levy IM, Pryor KW, McKeon TR. Is Teaching Simple Surgical Skills Using an Operant Learning Program More Effective Than Teaching by Demonstration? Clin Orthop Relat Res 2016;474:945-55.

7. Hoffman RL, Hudak-Rosander C, Datta J, et al. Goal orientation in surgical residents: a study of the motivation behind learning. J Surg Res 2014;190:451-6.

8. Anderson CI, Gupta RN, Larson JR, et al. Impact of objectively assessing surgeons' teaching on effective 
perioperative instructional behaviors. JAMA Surg 2013;148:915-22.

9. Chapman G. The Five Love Languages: How to Express Heartfelt Commitment to Your Mate. Chicago, IL:

Cite this article as: Cerfolio RJ, Ferrari-Light D. How to get the most out of your trainees in robotic thoracic surgery — "the coachability languages". Ann Cardiothorac Surg 2019;8(2):269273. doi: $10.21037 /$ acs.2018.12.05
Northfield Publishing, 1995.

10. DaRosa DA, Zwischenberger JB, Meyerson SL, et al. A theory-based model for teaching and assessing residents in the operating room. J Surg Educ 2013;70:24-30. 